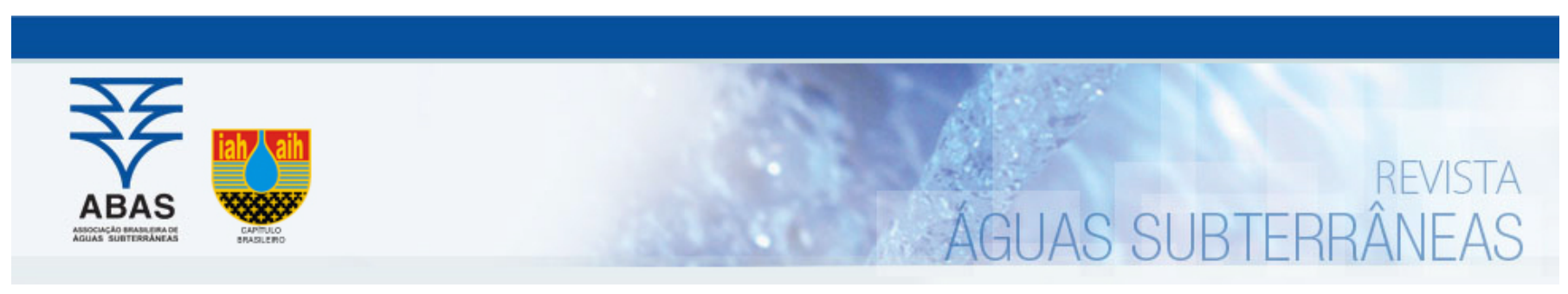

Artigos

\title{
Riscos de impactos ambientais proveniente da deposição irregular de Resíduos da Construção Civil em bacias hidrográficas da Região Metropolitana do Recife
}

\section{Risks of environmental impacts arising from the irregular deposition of Civil Construction Waste in the Metropolitan Region of Recife watersheds}

\author{
Diogo Paz1; Kalinny Lafayette2,1; Maria do Carmo Sobral1; Maria Júlia Holanda2,1; Tiana Ximenes1 ${ }^{\bowtie}$ \\ 1 Universidade Federal de Pernambuco (UFPE), Recife \\ 2 Poli/Universidade Federal de Pernambuco (UFPE), Recife

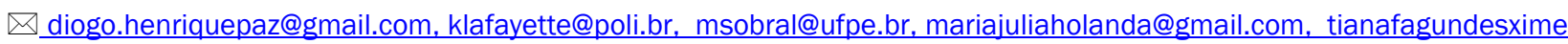 \\ nes@gmail.com
}

\begin{tabular}{|c|c|}
\hline & Resumo \\
\hline \multirow[t]{2}{*}{$\begin{array}{l}\text { Palavras-chave: } \\
\text { Impactos Ambientais. } \\
\text { Resíduos de construção. } \\
\text { Recursos hídricos. }\end{array}$} & $\begin{array}{l}\text { A deposição irregular dos Resíduos da Construção Civil (RCC) ocasiona uma série de impactos ambientais nos recursos hídricos } \\
\text { como problemas à saúde, poluição das águas e do solo, e danos estéticos às cidades. Esta pesquisa tem como objetivo mapear } \\
\text { os pontos de deposição irregular de RCC na Região Metropolitana do Recife (RMR) e avaliar os impactos ambientais que os } \\
\text { mesmos ocasionam nas bacias hidrográficas Para a identificação das áreas foram realizadas incursões a } 7 \text { municípios da RMR, } \\
\text { onde foram mapeados os pontos de deposição, sendo posteriormente plotados no software Google Earth. Após a coleta dos } \\
\text { dados, foram identificados } 1252 \text { pontos, os quais foram divididos em classes de risco para analisar quais áreas possuem um } \\
\text { maior risco de ocasionar impactos ambientais. Verificou-se que a bacia Grupos Litorâneos } 1 \text { (GL1) apresenta mais áreas de alto } \\
\text { impacto ambiental, e que a bacia do Capibaribe possui a maior quantidade de pontos de deposição irregular. Apenas dois pontos } \\
\text { possuem impacto ambiental muito alto, um localizado no município do Cabo de Santo Agostinho, e outro no município de Olinda. } \\
\text { Conclui-se que há uma grande necessidade de implantação de um plano integrado de gerenciamento dos RCC na RMR, como } \\
\text { também de maior fiscalização por parte dos comitês de bacia. }\end{array}$ \\
\hline & Abstract \\
\hline $\begin{array}{l}\text { Construction waste. } \\
\text { Environmental impacts. } \\
\text { Water resources. }\end{array}$ & $\begin{array}{l}\text { The irregular disposal of Construction Waste (CW) causes a series of environmental impacts on water resources, such as damage } \\
\text { to health, pollution of water, soil and aesthetics to cities. The objective of this research is to map the irregular deposition sites of } \\
\mathrm{CW} \text { in the Metropolitan Region of Recife (MRR) and to evaluate the environmental impacts they cause on the watersheds. In order } \\
\text { to identify the areas, the incursions were made to } 7 \text { municipalities studied, where the disposal points were identified, and plotted } \\
\text { on Google Earth software. After data collection, } 1252 \text { points were identified, and were divided in risks classes to analyze which } \\
\text { areas have a greater risk of causing environmental impacts. It was verified that the Grupos Litorâneos } 1 \text { (GL1) watershed presents } \\
\text { more areas of high environmental impact, and the Capibaribe watersehd has the highest amount of irregular disposal points. Only }\end{array}$ \\
\hline $\begin{array}{l}\text { Revisado por pares. } \\
\text { Recebido em: 10/05/2018. } \\
\text { Aprovado em: 30/08/2018. }\end{array}$ & $\begin{array}{l}\text { two points have a very high environmental impact, one located in the municipality of Cabo de Santo Agostinho, and another in the } \\
\text { municipality of Olinda. It is concluded that there is a great need to implement an integrated management plan for CW in MRR, as } \\
\text { well as greater monitoring by the basin committees. }\end{array}$ \\
\hline
\end{tabular}

DOI: http://dx.doi.org/10.14295/ras.v32i3.29149

\section{INTRODUÇÃO}

Dentre os impactos ambientais ocasionados pela indústria da construção civil, estão os advindos da deposição inadequada dos resíduos de construção civil (RCC), que tem se tornado um grande problema enfrentado pelas cidades brasileiras (ESA et al., 2016), podendo ocasionar problemas à saúde, poluição dos recursos hídricos e do solo, e danos estéticos às cidades.
No Brasil, a Resolução do CONAMA n 307 (BRASIL, 2002), que define os critérios, diretrizes e procedimentos para a gestão dos resíduos da construção civil, estabelece, em seu Art. $4^{\circ}, \S 1^{\circ}$, que "os resíduos da construção civil não poderão ser dispostos em aterros de resíduos sólidos urbanos, em áreas de "bota fora", em encostas, corpos d'água, lotes vagos e em áreas protegidas por Lei", cabendo ao gerador gerenciar de forma correta a cole- 
ta, transporte e destinação final dos RCC.

Conforme aponta Wiens (2008), a gestão dos resíduos sólidos faz parte das ações de controle dos Comitês de Bacias Hidrográficas, em especial dos resíduos provenientes de construções e demolições, pois a deposição dos resíduos tem influência direta na qualidade da água da bacia. Júnior et al. (2015) apontam que o tratamento inadequado dos resíduos são umas das principais fontes de contaminantes das águas subterrâneas.

A Região Metropolitana do Recife (RMR), assim enfrenta a problemática relacionada aos RCC que, "em sua maioria, ultrapassam a geração de resíduos sólidos domiciliares” (SANTOS et al., 2010).

Um dos principais impactos causados pelos RCC na RMR é o assoreamento de rios e córregos, contaminação do lençol freático e obstrução dos canais de drenagem de águas pluviais, que comumente causam enchentes devastadoras (LAWSON et al., 2001).

De acordo com Lawson et al. (2001), os resíduos provenientes de novas construções geralmente são limpos e sem presença de contaminantes, enquanto que os resíduos de demolição estão geralmente contaminados e misturados com outros materiais, de modo que uma série de substâncias perigosas ou potencialmente perigosas possam estar presentes. Em especial, os contaminantes que são solúveis e podem ser absorvidos em materiais de construção porosos, que provavelmente estão presentes em águas subterrâneas ou superficiais contaminadas.

Córdoba (2014) afirma que existe potencial de contaminação dos lixiviados gerados em aterros de RCC, os quais podem vir a poluir ou contaminar o solo e as águas subterrâneas, inviabilizando a utilização dessas águas para consumo humano. Porém, observou em seu experimento que os locais contendo apenas Classe A (concreto, cerâmicos, solo), apresentaram parâmetros como alcalinidade, cálcio, magnésio, zinco, cobre, dentre outros, superiores do que os RCC de outras classes.

Algumas pesquisas voltadas para a identificação da deposição irregular de RCC na RMR já foram realizadas. Santos (2015) realizou um mapeamento de 101 pontos de deposição de RCC no município de Jaboatão dos Guararapes, e identificou que os impactos ambientais afetam principalmente o meio social e econômico, gerando altos custos nas despesas municipais.

Albuquerque (2015) também realizou um estudo dos impactos ambientais ocasionados por 184 pontos na cidade do Recife, verificando que o espaço de área de preservação permanente (APP) e cursos d'água se destacaram como variável de maior magnitude de impacto, e constatando ainda um significativo número de ocorrências de resíduos perigosos nestes locais.
Neste sentido, surge a necessidade de realizar um diagnóstico da real situação da deposição irregular de RCC na RMR, a fim de dar subsídios para os gestores municipais na elaboração dos planos diretores e critérios de zoneamento, visando preservar a qualidade das águas superficiais e subterrâneas, e minimizar a contaminação de aquíferos.

Esta pesquisa tem como objetivo realizar uma análise dos riscos de impactos ambientais provenientes da deposição irregular de RCC em bacias hidrográficas da RMR, de modo a identificar as áreas mais críticas e elencar os pontos que existe prioridade de coleta, devido ao seu risco de contaminação.

\section{METODOLOGIA}

\subsection{Caracterização da área de estudo}

A Região Metropolitana do Recife (RMR), situada na extremidade leste de Pernambuco, é composta por 14 municípios (Recife, Olinda, Paulista, Abreu e Lima, Igarassu, Itapissuma, Ilha de Itamaracá, Araçoiaba, Ipojuca, Cabo de Santo Agostinho, Moreno, São Lourenço da Mata, Camaragibe e Jaboatão dos Guararapes), acrescida do Distrito de Fernando de Noronha. Com uma área de $2.785,44$ km² $^{2}$ e população total de 3.693.177 habitantes (IBGE, 2010), apresenta uma densidade demográfica de 1.325,89 hab/km².

Existem 6 bacias hidrográficas que desaguam na faixa litorânea da RMR (Sirinhaém, Ipojuca, Capibaribe, Grupos Litorâneos 1 - GL1, Grupos Litorâneos 2 - GL2, e Grupos Litorâneos 3 - GL3), conforme apresenta a Figura 1.

Para compor esta pesquisa foi definida como área de estudo as bacias do Capibaribe, GL1 e GL2. Esta escolha se justifica pelo fato de abranger os principais municípios da RMR, onde foi realizada a pesquisa: Recife, Jaboatão dos Guararapes, Olinda, Paulista, Camaragibe, São Lourenço da Mata e Cabo de Santo Agostinho (Figura 2). 
Figura 1 - Bacias hidrográficas da RMR

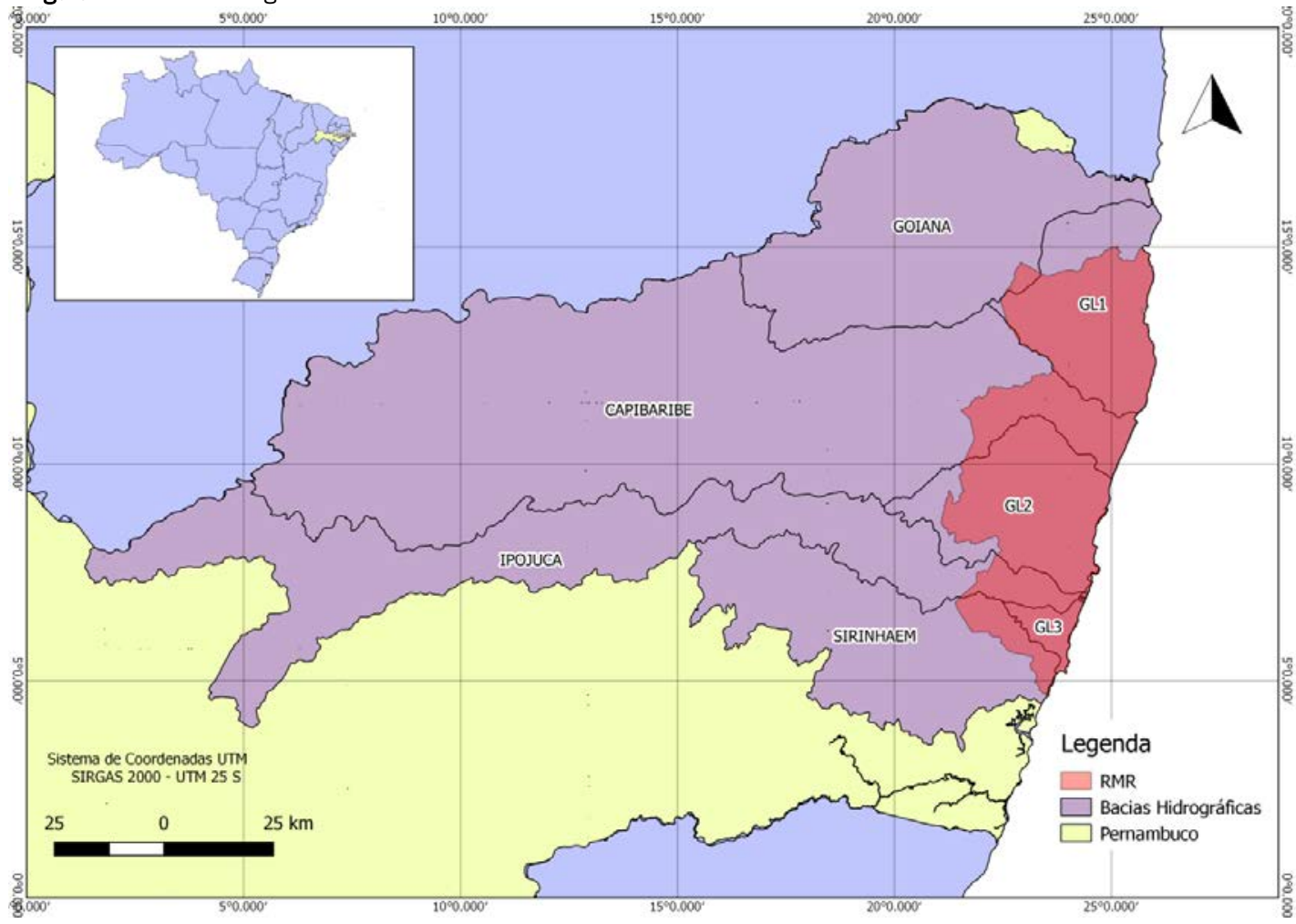

Figura 2 - Localização da área de estudo

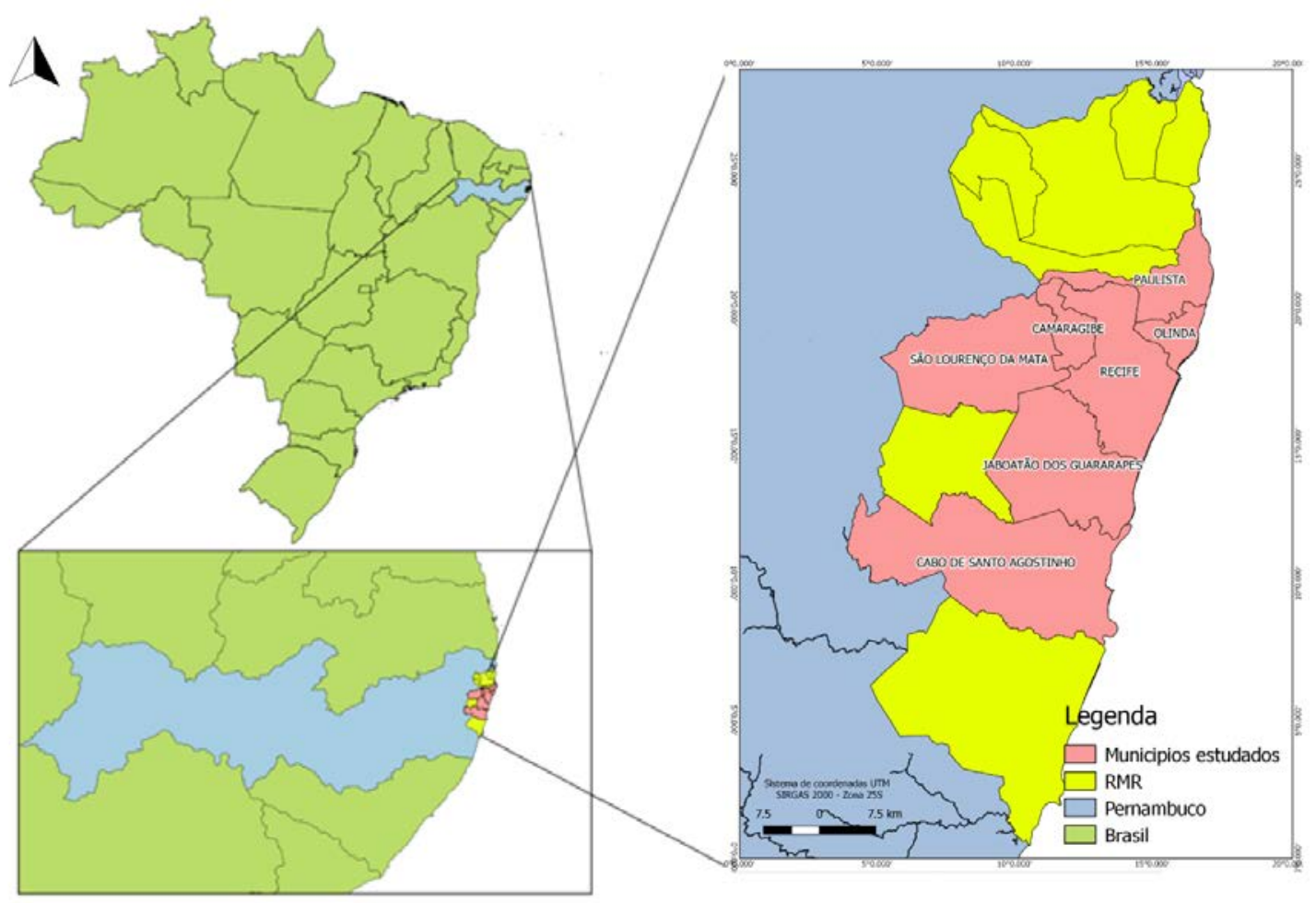


Em relação aos recursos hídricos, predomina na RMR a captação de águas superficiais de vários reservatórios, complementada por meio de aquíferos que se estendem pela faixa costeira do Estado (BORBA et al., 2010).

Atualmente, a RMR registra significativos sinais de degradação ambiental, especificamente o desmatamento, deposição inadequada de resíduos sólidos, contaminação/salinização dos recursos hídricos superficiais e subterrâneos, emissão de poluentes atmosféricos, poluição visual, escorregamentos e erosão de encostas, alagamentos de áreas de planície e a erosão costeira, todos resultantes da ação antrópica, devido à falta de gestão adequada das bacias hidrográficas da região (PERNAMBUCO, 2011).

\subsection{Classificação dos riscos de impactos ambientais}

Para identificar as áreas com maior risco de impactos ambientais nas bacias hidrográficas estudadas realizou-se um levantamento de campo para mapeamento dos pontos de deposição irregular de RCC por meio de registro fotográfico e georreferenciamento, nos municípios pertencentes às bacias do Capibaribe, GL1 e GL2.

A partir da identificação dos pontos de deposição, foram registradas as coordenadas geográficas com um aparelho de GPS (Global Positioning System), sendo posteriormente plotados no software Google Earth e QGIS 2.8.1, onde foi realizada uma caracterização dos pontos, de acordo com os tipos de resíduos encontrados (Classe A, B, C e D, conforme a Resolução $n^{\circ}$ 307/2002 do CONAMA), e caracterização em relação aos bairros, tipos de pavimentação existente, vegetação, entre outros.

Além disso, foram identificadas as características socioeconômicas de cada município como população, domicílios particulares permanentes e renda média, de forma a correlacionar os pontos de deposição irregular de resíduos às características da área. Os dados de características socioeconômicas de cada região foram obtidos na Base de Informações do Censo Demográfico (IBGE, 2010).

Como forma de analisar quais áreas são mais vulneráveis a ocasionar impactos ambientais e que, portanto, devem ter uma atenção especial por parte dos órgãos ambientais e comitês de bacia, foi realizada uma classificação a partir dos parâmetros de recursos hídricos, áreas de proteção, declividade, hidrogeologia e pedologia, baseado nas pesquisas de Ornelas (2011) e Biju (2015), adaptando-se para a definição de pontuações de impacto de acordo com a distância dos pontos de deposição irregular.

Quanto aos recursos hídricos, utilizou-se este critério já que a deposição irregular de RCC pode comprometer o sistema hidrográfico e drenagem, tendo como consequência o assoreamento e inundação, bem como transtornos à saúde pública, ao favorecer a ocorrência doenças de veiculação hídrica (CÓRDOBA, 2014).

Para a classificação dos riscos de impactos nos recursos hídricos, utilizou-se como base as Faixas de Margem de Proteção (FMP) do Novo Código Florestal (Lei $n^{\circ}$ 12.651/2012) em seu Art. $4^{\circ}$, que define as Áreas de Preservação Permanente (APP). Os corpos hídricos das bacias analisadas possuem uma largura média entre 50 e 100m, observado por meio de ferramentas de geoprocessamento, informação necessária para definição da FMP mínima nas bacias hidrográficas estudadas.

Quanto às áreas protegidas, a Lei $n^{\circ}$ 9.985/2000, que estabelece o Sistema Nacional de Unidades de Conservação (SNUC), determina em seu Art. 25 que as unidades de conservação devem possuir zonas de amortecimento que, de acordo com o Art. $2^{\circ}$, são "o entorno de uma unidade de conservação, onde as atividades humanas estão sujeitas a normas e restrições específicas, com o propósito de minimizar os impactos negativos sobre a unidade". Nesse caso, estabeleceu-se como parâmetro uma distância mínima de 300 metros das áreas protegidas, baseado em planos de manejo de UCs existentes no estado, para diminuir os impactos que possam ser gerados pela deposição irregular de RCC.

O parâmetro de declividade foi estabelecido considerando que as áreas menos inclinadas favorecem o acesso dos caminhões para operações de coleta dos resíduos e recuperação da área, bem como reduzem o escoamento de chorume dos resíduos orgânicos que possam estar misturados aos RCC. Definiu-se, portanto, que quanto maior a declividade, maior o risco de impacto (ORNELAS, 2011, adaptado).

Em relação à pedologia, considerou-se a fragilidade como parâmetro, baseado em Biju (2015) e Bohnenberger et al. (2018), que pode favorecer a degradação ambiental por meio da percolação de contaminantes provenientes dos RCC.

Quanto ao parâmetro de hidrogeologia, considerou-se a vulnerabilidade à contaminação, conforme classificação definida pela CPRM (1994) e SECTMA (2006).

Os arquivos vetoriais e matriciais utilizados na pesquisa foram provenientes de diferentes fontes. Os dados referentes aos recursos hídricos foram obtidos do Instituto Brasileiro de Geografia e Estatística (IBGE, 2017); o arquivo de pedologia foi proveniente da Empresa Brasileira de Pesquisa Agropecuária (EMBRAPA, 2017); o de declividade do Instituto Nacional de Pesquisas Espaciais (INPE, 2017); o de hidrogeologia foi obtido junto à Companhia de Pesquisa e Recursos Minerais (CPRM, 2017), enquanto que o de áreas protegidas foi obtido do SIG Caburé, sistema de informações geoambientais de Pernambuco, criado pela Agência Estadual de Meio Ambiente (CPRH, 2017).

Todos os dados foram organizados em um Banco de Dados no software QGIS, adotando-se como sistema de referência cartográfica o SIRGAS 2000/UTM Zona 25s.

O Quadro 1 apresenta a atribuição de pesos proposta nesta pesquisa para análise dos riscos de impactos ambientais, de acordo com o que aponta a legislação ambiental pertinente e pesos utilizados por outros autores (BIJU, 2015; BOHNENBERGER et al., 2018). Quanto mais próximos estiverem os resíduos, maior a pontuação e, portanto, maior o risco de impacto ambiental. A delimitação dos limites de distância foi realizada com o auxílio da ferramenta buffer do software QGIS. 
Quadro 1 - Classificação dos parâmetros de acordo com o critério de distância dos pontos

\begin{tabular}{|c|c|}
\hline Parâmetros & Score \\
\hline Recursos Hídricos & $\begin{array}{c}\text { Distância } \\
0 \text { a } 50 m-5,0 \\
51 \text { a } 200 m-3,0 \\
>200 m-1,0\end{array}$ \\
\hline Áreas protegidas & $\begin{array}{c}\text { Distância } \\
0 \text { a } 50 m-5,0 \\
50 \text { a } 300 m-3,0 \\
>300 m-1,0\end{array}$ \\
\hline Declividade & $\begin{array}{c}\text { Inclinação } \\
0-3 \% \text { (Plano) - 1,0 } \\
3-8 \% \text { (Suave Ondulado) - 2,0 } \\
8-20 \% \text { (Ondulado) }-3,0 \\
20-45 \% \text { (Forte Ondulado) - 4,0 } \\
45-75 \% \text { (Montanhoso) }-5,0\end{array}$ \\
\hline Pedologia & $\begin{array}{c}\text { Fragilidade } \\
\text { Muito baixa }-1,0 \\
\text { Baixa }-2,0 \\
\text { Média }-3,0 \\
\text { Forte }-4,0 \\
\text { Muito Forte }-5,0\end{array}$ \\
\hline Hidrogeologia & $\begin{array}{c}\text { Vulnerabilidade } \\
\text { Baixa - 1,0 } \\
\text { Moderada }-3,0 \\
\text { Alta }-5,0\end{array}$ \\
\hline
\end{tabular}

Com os valores definidos, adotou-se a metodologia de análise multicritério, que utiliza uma equação para somar o score (pontuação) de cada parâmetro, utilizando-se a ferramenta de álgebra de mapas no software QGIS (Calculadora Raster), conforme apresenta a Equação 1.

$$
S_{\text {par }}=S_{\text {rh }}+S_{\text {ap }}+S_{d}+S_{s}+S_{h g}
$$

Onde: $\mathrm{S}_{\mathrm{par}}=$ Score total dos parâmetros;

$\mathrm{S}_{\mathrm{rh}}=$ score de distância dos recursos hídricos;

$\mathrm{S}_{\mathrm{ap}}=$ score de distância das áreas protegidas;

$\mathrm{S}_{\mathrm{d}}=$ score de acordo com a declividade;

$\mathrm{S}_{\mathrm{s}}=$ score de acordo com a pedologia;

Shg $=$ score de acordo com a hidrogeologia.

Além do score devido aos parâmetros, foi proposto nesta pesquisa um score de acordo com o porte das pilhas de RCC, conforme apresenta a Tabela 1. Foram considerados como pontos pequenos aqueles advindos de pequenos geradores, ou seja, que geram menos de 1 $\mathrm{m}^{3} /$ dia de resíduos, cuja responsabilidade de coleta é da prefeitura (RECIFE, 2013). Os pontos de tamanho médio ( $2 \mathrm{~m}^{3}$ a $\left.6 \mathrm{~m}^{3}\right)$ são aqueles que preenchem uma caçamba estacionária de $6 \mathrm{~m}^{3}$, enquanto que os pontos de grande porte são aqueles que precisam de mais de uma caçamba estacionária para serem coletados, sendo geralmente os pontos consolidados que estão em terrenos baldios.

Tabela 1 - Score dos pontos devido ao porte da pilha de resíduos

\begin{tabular}{cc}
\hline Porte & Score \\
\hline Pequeno & 2,0 \\
Médio & 3,0 \\
Grande & 4,0 \\
\hline
\end{tabular}

O score final dos riscos de impactos ambientais de cada ponto de deposição irregular foi calculado de acordo com a Equação 2.

$$
\mathrm{S}_{\mathrm{f}}=\mathrm{S}_{\mathrm{par}} * \mathrm{~S}_{\mathrm{por}}
$$

Onde: $\mathrm{S}_{\mathrm{f}}=$ Score final de risco de impacto ambiental; $\mathrm{S}_{\mathrm{por}}=$ score devido ao porte da pilha de resíduos

O score final varia de 10 a 100 pontos; o valor do score final define a classe de riscos de impactos ambientais de cada ponto de deposição irregular, as quais propõe-se nesta pesquisa a divisão em quatro classes, conforme apresenta a Tabela 2 .

Tabela 2 - Classes de risco de impacto e as respectivas pontuações

\begin{tabular}{lcc}
\hline Classificação & Escala & Score final \\
\hline Classe I & Impacto Baixo & 10 a 25 \\
Classe II & Impacto Médio & 26 a 50 \\
Classe III & Impacto Alto & 51 a 75 \\
Classe IV & Impacto Muito Alto & 76 a 100 \\
\hline
\end{tabular}

Fonte: Elaborado pelo autor

Todo o cálculo dos scores foi realizado através da utilização de álgebra de mapas no software QGIS 2.14.

\section{RESULTADOS E DISCUSSÃO}

A coleta de dados registrou um total de 1252 pontos de deposição irregular de RCC distribuídos nos municípios de Recife, Jaboatão dos Guararapes, Cabo de Santo Agostinho, Paulista, Olinda, Camaragibe e São Lourenço da Mata. 
A Tabela 3 apresenta a quantidade de pontos de deposição irregular de RCC mapeados nas bacias hidrográficas, em com- paração com a área urbana, e a Figura 3 mostra a quantidade de pontos levantados por $\mathrm{km}^{2}$ de cada bacia hidrográfica.

Tabela 3 - Quantidade de pontos de deposição irregular de RCC mapeados na RMR

\begin{tabular}{ccccc}
\hline Bacias & $\begin{array}{c}\text { Área total dentro } \\
\text { da RMR }\left(\mathrm{km}^{2}\right)\end{array}$ & $\begin{array}{c}\text { Área urbanizada dentro } \\
\text { da RMR }\left(\mathrm{km}^{2}\right)\end{array}$ & $\begin{array}{c}\text { \% de área } \\
\text { urbanizada }\end{array}$ & $\begin{array}{c}\text { Pontos de deposição } \\
\text { irregular de RCC }\end{array}$ \\
\hline Capibaribe & 415,64 & 179,2 & 44,2 & 662 \\
GL1 & 224,3 & 50,1 & 22,2 & 360 \\
GL2 & 734,2 & 118,4 & 16,1 & 230 \\
\hline TOTAL & $1.374,25$ & 388,1 & - & 1252 \\
\hline
\end{tabular}

Figura 3 - Quantidade de pontos de RCC por $\mathrm{km}^{2}$ de área urbanizada nas bacias hidrográficas estudadas

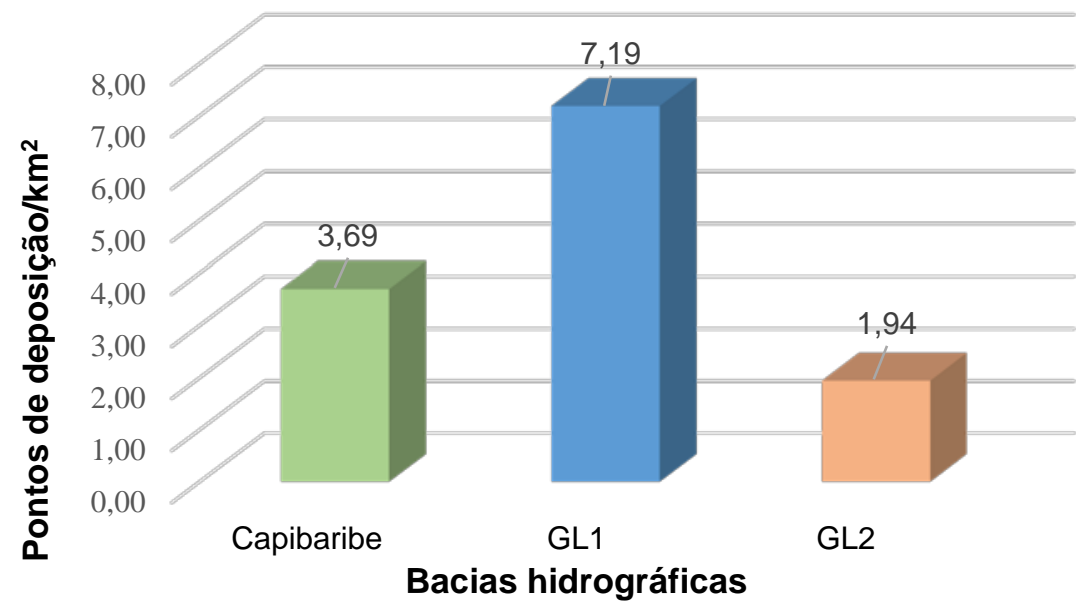

Observa-se que a quantidade de pontos de deposição mapeados segue a lógica da quantidade de área urbanizada em cada bacia: na bacia do Capibaribe, que possui quase metade de sua área na RMR ocupada por áreas urbanas $(44,2 \%)$, foram registradas a maior parte dos pontos de deposição (52,8\%).

Por outro lado, a bacia GL1 apresenta a maior concentração de pontos de deposição irregular de RCC $\left(7,19\right.$ pontos $\left./ \mathrm{km}^{2}\right)$, em especial no município de Paulista, que possui 139 pontos de deposição inseridos dentro da bacia (Figura 4).
A Figura 5 apresenta o tamanho dos pontos de deposição irregular nas bacias hidrográficas por observação direta; foi verificado que metade dos pontos (630 pontos) são de médio porte, ou seja, podem ser coletados com apenas uma caçamba estacionária. 
Figura 4 - Pontos de deposição irregular de RCC mapeados nos municípios estudados

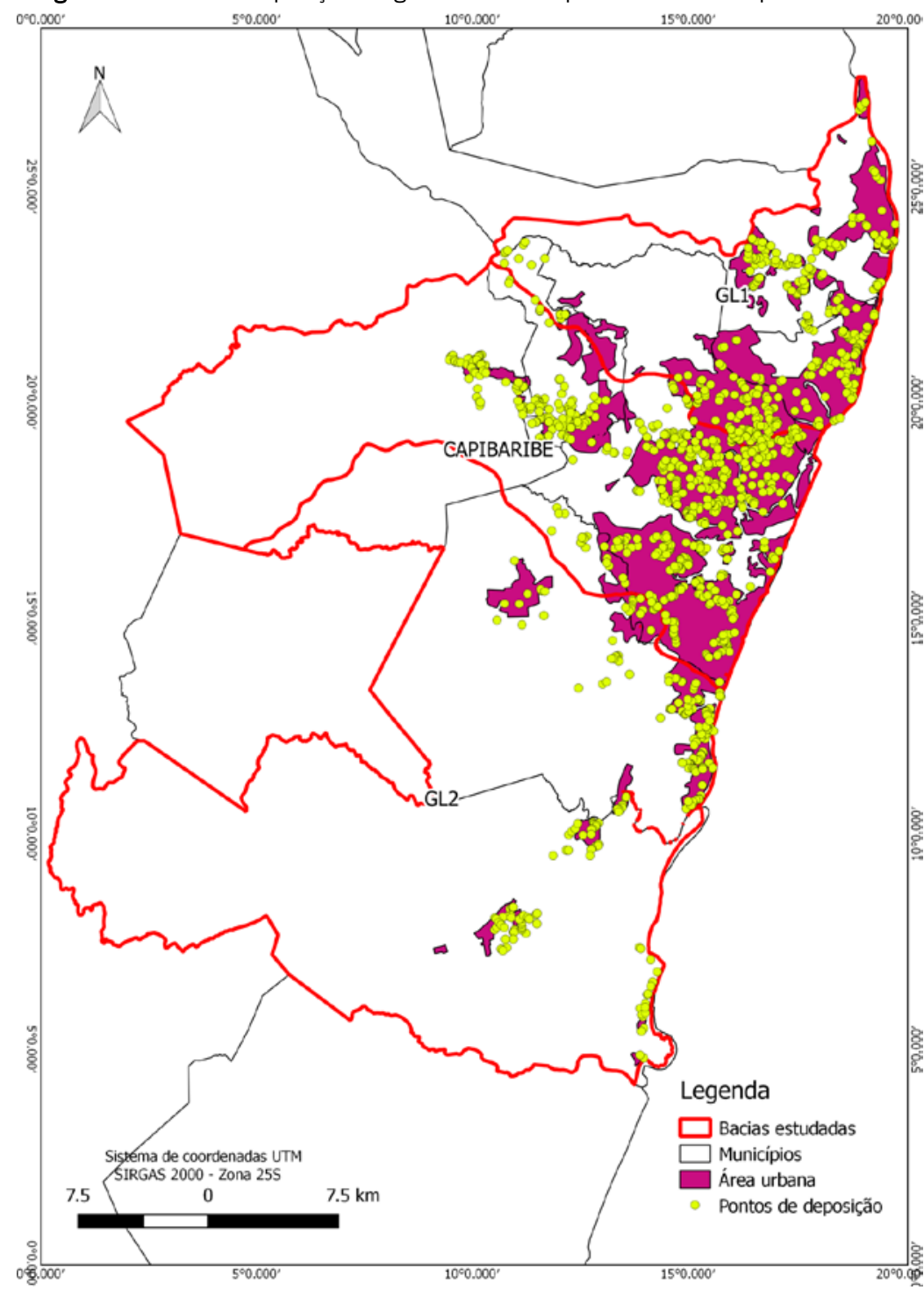

Figura 5 - Porte dos pontos de deposição irregular nas bacias da RMR

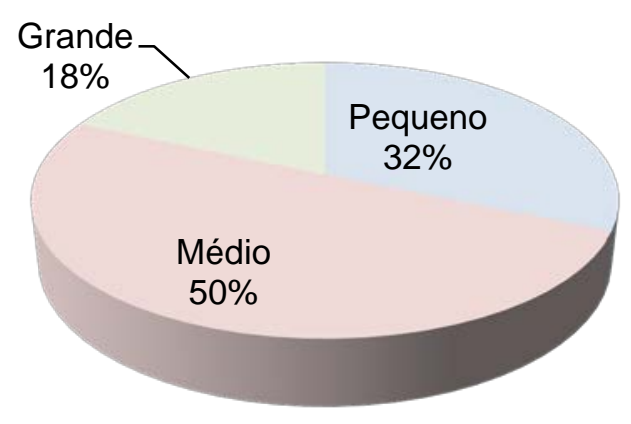

A Tabela 4 apresenta a distribuição dos pontos de deposição irregular conforme o porte em cada bacia hidrográfica. Quanto aos pontos de de- posição de grande porte, $57 \%$ (129 pontos) localizam-se na bacia hidrográfica do Capibaribe. 
Tabela 4 - Percentagem de pontos de deposição irregular por bacia em relação ao porte.

\begin{tabular}{cccc}
\hline \multirow{2}{*}{ Municípios } & \multicolumn{3}{c}{ Porte das pilhas de resíduos } \\
\cline { 2 - 4 } & Pequeno (\%) & Médio (\%) & Grande (\%) \\
\hline Capibaribe & 32 & 48 & 20 \\
GL1 & 31 & 52 & 17 \\
GL2 & 30 & 54 & 16 \\
\hline
\end{tabular}

Observou-se que os pontos de grande porte são aqueles situados em locais já consolidados, nos quais a população e algumas construtoras têm a prática de descartar os resíduos provenientes de construções, resíduos domésticos, resíduos volumosos e resíduos perigosos, além daqueles provenientes de poda de árvore. São áreas em que se torna bastante onerosa a coleta dos resíduos e se impossibilita a reciclagem devido à grande mistura de materiais.

Os pontos de deposição considerados como de pequeno porte são as pilhas de entulho provenientes de pequenas reformas, que são deixadas na calçada para serem recolhidas pela prefeitura.
Em alguns locais foi observada a proximidade dos resíduos aos cursos d'água, como apresenta a Figura 6, onde os RCC estão depositados na beira do canal de Fragoso, no município de Olinda/PE, área onde frequentemente ocorrem enchentes no período chuvoso.

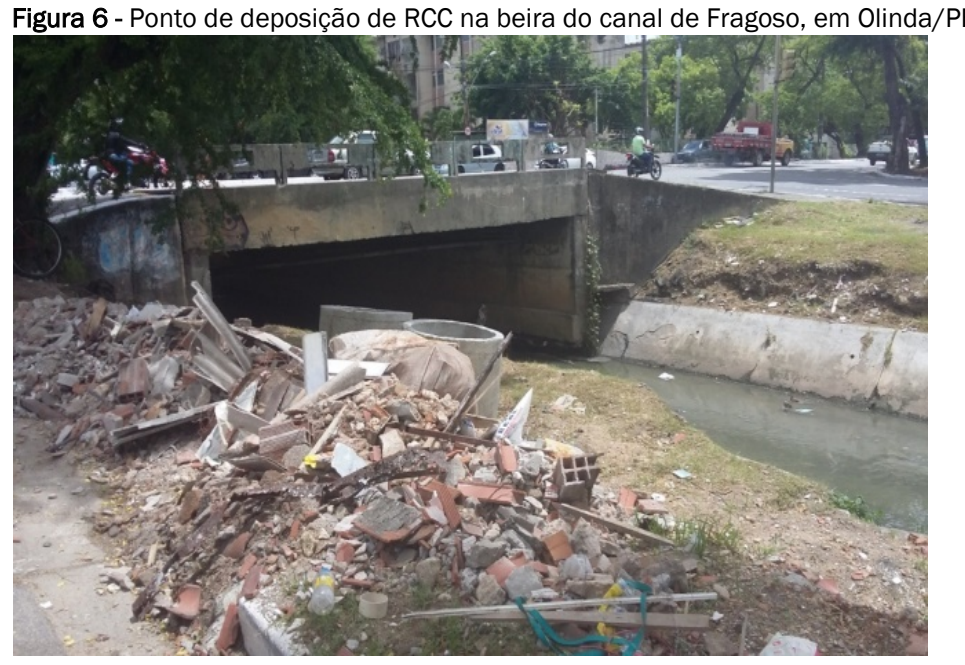

A partir da soma do score dos parâmetros utilizados, obteve-se a classificação dos riscos de impactos ambientais nas bacias hidrográficas do Capibaribe, GL1 e GL2, conforme apresenta a Figura 7.

Verificou-se que apenas 0,06\% da área de estudo foi classificada como de risco de impacto ambiental baixo - Classe I. Há uma maior predominância de áreas de impacto ambiental médio (47,6\%) - Classe II e alto (48\%) - Classe III. As áreas mais críticas (impacto ambiental muito alto - Classe IV) foram identificadas em 4,4\% do total da área de estudo, 0 que corresponde a $48 \mathrm{~km}^{2}$.
Analisando a imagem de classificação das áreas de riscos ambientais, verifica-se que a Bacia GL1 apresenta mais áreas de impacto ambiental alto (Classes III e IV) principalmente devido a grandes áreas protegidas, em especial a APA Aldeia-Beberibe, cujo território perpassa os municípios de Paulista, Recife, Camaragibe e São Lourenço da Mata.

As áreas próximas ao litoral também obtiveram um risco de impacto alto, devido às vulnerabilidades de recursos hídricos, pedologia, e hidrogeologia, que torna estas áreas de estuário mais suscetiveis a impactos ambientais provenientes da deposição irregular de RCD. 
Figura 7 - Classificação dos riscos de impactos ambientais nas bacias hidrográficas

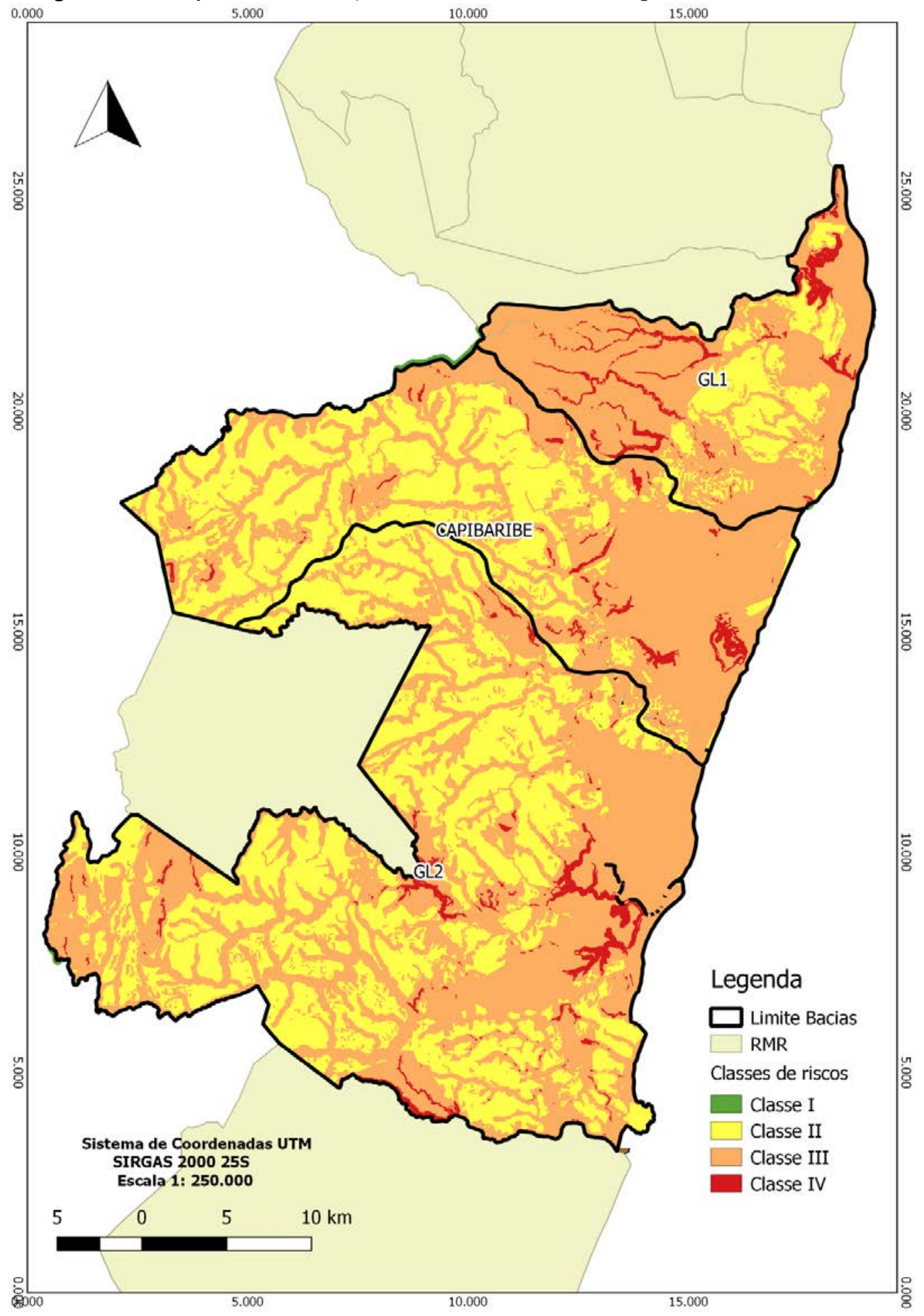

A Figura 8 apresenta a classificação final de cada ponto de deposição drográficas, após o cálculo entre a localização e o porte dos irregular em relação aos riscos de impactos ambientais nas bacias hipontos. 
Figura 8 - Classificação final dos pontos de deposição irregular de RCC

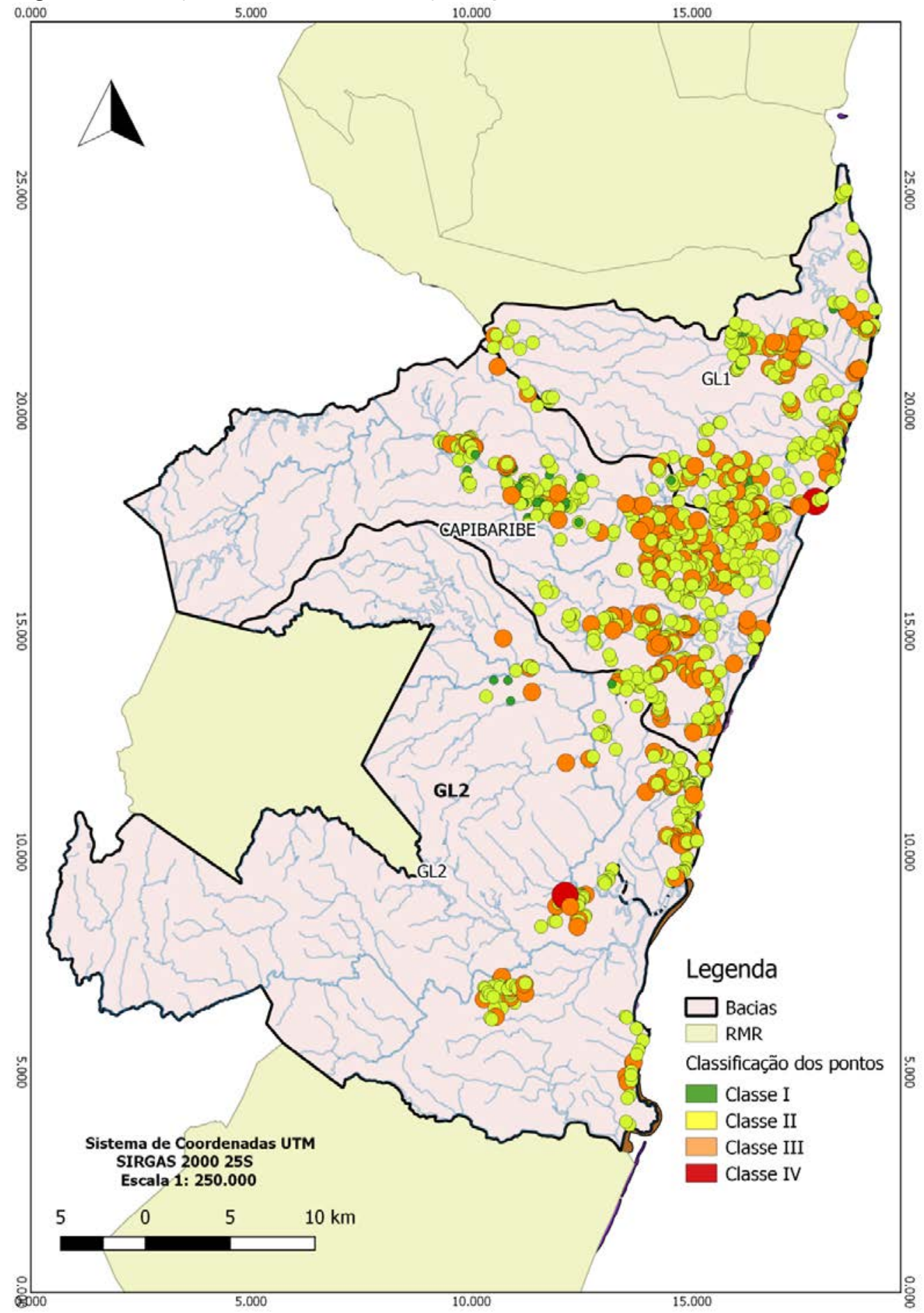

A partir da classificação obteve-se que 64 pontos (5\%) são considerados como de impacto ambiental baixo. Por outro lado, a grande maioria (966 pontos) são de impacto médio (77\%), 220 pontos são de impacto alto (18\%), e apenas 2 pontos foram classificados como de impacto muito alto, um localizado no município do Cabo de Santo Agostinho (Bacia GL2), por ser de grande porte, localizado em área protegida; e outro no município de Olinda (Bacia GL1), por ser de grande porte, às margens do rio Beberibe.
Como forma de avaliar a situação dos riscos de impactos ambientais em cada município e dar subsídios à tomada de decisão acerca da coleta dos RCC, a Tabela 5 descreve a quantidade de pontos por classe e por município estudado. 
Tabela 5 - Classificação dos pontos por bacia hidrográfica

\begin{tabular}{ccccc}
\hline \multirow{2}{*}{ Municípios } & \multicolumn{4}{c}{ Classes de riscos de impacto } \\
\cline { 2 - 5 } & Classe I & Classe II & Classe III & Classe IV \\
\hline Capibaribe & 40 & 506 & 116 & 0 \\
GL1 & 20 & 276 & 63 & 1 \\
GL2 & 4 & 184 & 41 & 1 \\
\hline TOTAL & 64 & 966 & 220 & 2 \\
\hline
\end{tabular}

A bacia do Capibaribe, portanto, possui a maior quantidade de RCC com risco de impacto médio e alto. Observou-se que 63 dos 116 pontos de Classe III (Impacto Alto) estão localizados às margens do rio Capibaribe (31\%), nos municípios de São Lourenço da Mata, Camaragibe e Recife. Isso ocorre devido à grande ocupação irregular das margens do rio, e às obras de grande porte em expansão às margens do rio Capibaribe em Recife. Os demais pontos estão localizados próximos a açudes e lagos.

Conforme aponta o Plano Hidroambiental da Bacia do rio Capibaribe (PERNAMBUCO, 2010), a geração total de resíduos sólidos na bacia era de aproximadamente 1.521 toneladas/dia, em 2010. De fato, o rio Capibaribe, ao chegar à RMR, recebe contribuições de esgoto doméstico e descarte de resíduos. Além disso, o sistema de drenagem urbana contribui com a deposição de resíduos no rio (PERNAMBUCO, 2011). Gava e Finotti (2012), ao realizarem uma quantificação de resíduos que alcança a rede de drenagem, observaram que os materiais de construção corresponderam a $43 \%$ dos resíduos retidos.

De acordo com dados do Plano Metropolitano de Resíduos Sólidos (PERNAMBUCO, 2011), são gerados na RMR cerca de 75 mil toneladas de RCC por mês, considerando que estes são responsáveis por $50 \%$ a $70 \%$ do total de resíduos gerados.

Em relação ao parâmetro de hidrogeologia, observou-se que $69 \%$ dos pontos estão localizados em áreas de maior risco de contaminação das águas subterrâneas, como os depósitos aluvionares, sedimentos de mangue e formação Beberibe (SECTMA, 2006).

A RMR, especificamente as cidades de Recife, Olinda e Jaboatão dos Guararapes, possui hoje cerca de 11 mil poços que captam água subterrânea dos aquíferos Beberibe, Cabo e Boa Viagem. Somente no Recife, estima-se mais de 6.000 poços em operação (COSTA FILHO et al. 2010; APAC, 2016). Estes números, associados com os resultados obtidos pela classificação de riscos, aponta para um cenário preocupante de saúde pública, visto que há um aumento substancial na geração de RCC, e nos estudos que apontam o risco de contaminação das águas por estes resíduos.

\section{CONCLUSÕES}

Conforme a classificação final dos riscos de impactos ambientais nas bacias hidrográficas da RMR, pode-se considerar que em todas as bacias estudadas foram identificadas deposições de alto risco de impacto ambiental, muito embora a maior parte das deposições tenha sido classificada como de médio impacto ambiental.

Verificou-se que a situação mais preocupante em termos de risco de impacto ambiental é a bacia do Capibaribe, por possuir a maior área urbana das bacias e, consequentemente, a maior população, aumen- tando os riscos de danos à saúde. Porém, a concentração de pontos identificados na bacia GL1 aponta para um controle inadequado da geração e destinação final de RCC nos municípios do Cabo de Santo Agostinho e Jaboatão dos Guararapes.

Devido à ausência de dados concretos acerca da situação das águas subterrâneas da RMR, não é possível correlacionar a prática da deposição irregular de RCC com a degradação da qualidade da água subterrânea. Porém, a metodologia desenvolvida nesta pesquisa favorece a identificação das áreas mais suscetíveis à contaminação das águas, assim como permite sua aplicação em outras áreas de estudo.

Os resultados obtidos por esta pesquisa apontam para uma demanda ainda maior de estudos relacionados à presença de materiais perigosos nos RCC, e índices de contaminação dos aquíferos devido à deposição irregular.

Em virtude desse diagnóstico, percebe-se a necessidade clara de implantação de um plano integrado de gerenciamento dos RCC na RMR. Além disso, deve estar previsto nos planos diretores dos municípios, bem como nos planos de bacia, ações de preventivas e corretivas acerca da deposição irregular de resíduos sólidos.

\section{REFERÊNCIAS}

ALBUQUERQUE, D.M.S. Impacto socioambiental da disposição irregu lar dos resíduos da construção e demolição na cidade do Recife. 2015. 184 p. Dissertação (Mestrado em Engenharia Civil) - Escola Politécnica de Pernambuco, Universidade de Pernambuco. Recife, 2015.

APAC - AGÊNCIA PERNAMBUCANA DE ÁGUAS E CLIMA. Estudos sobre a disponibilidade e vulnerabilidade dos recursos hídricos subterrâneos da Região Metropolitana do Recife. Relatório das atividades 6 e 7. Recife, 2016.

BIJU, B.P. Utilização do Sistema de Informações Geográficas (SIG) na indicação de possíveis áreas aptas à disposição de resíduos de construção e de demolição. 2015. 114 p. Dissertação (Mestrado em Engenharia Civil) - Universidade Tecnológica Federal do Paraná. Curitiba, 2015.

BRASIL. Lei $n^{\circ}$ 12.651, de 25 de Maio de 2012. Dispõe sobre a proteção da vegetação nativa; altera as leis $n^{\circ} 6.938$, de 31 de agosto de 1981, 9.393, de 19 de dezembro de 1996, e 11.428, de 22 de dezembro de 2006; revoga as leis $n^{\circ} 4.771$, de 15 de setembro de 1965 , e 7.754, de 14 de abril de 1989, e a Medida Provisória n².166-67, de 24 de agosto de 2001, e dá outras providências. Diário Oficial da República Federativa do Brasil, 2012.

. Lei $n^{\circ}$ 9.985, de 18 de Julho de 2000. Regulamenta o art. $225 \S 1^{\circ}$, incisos I, II, II e VII da Constituição Federal, institui o Sistema Nacional de Unidades de Conservação da Natureza e dá outras providências. Diário Oficial da República Federativa do Brasil, 2010. 
Resolução CONAMA n 307, de 05 de julho de 2002. Estabelece diretrizes, critérios e procedimentos para a gestão dos resíduos da construção civil. Diário Oficial da Republica Federativa do Brasil, 2002.

BOHNENBERGER, J.C.; PIMENTA, J.F.P.; ABREU, M.V.S.; COMINI, U.B.; CALIJURI, M.L.; MORAES, A.P.; PEREIRA, I.S. Identificação de áreas para implantação de usina de reciclagem de resíduos da construção e demolição com uso de análise multicritério. Ambiente construído, v. 18, n. 1, p. 299-311, jan./mar. 2018.

BORBA, A.L.S.; COSTA FILHO, W.D.; MASCARENHAS, J.C. Configuração geométrica dos aquíferos da Região Metropolitana do Recife. In: Congresso Brasileiro de Águas Subterrâneas, 16, 2010, São Luís. Anais... São Luís: ABAS, 2010.

CÓRDOBA, R.E. Estudo do potencial de contaminação de lixiviados gerados em aterros de resíduos da construção civil por meio de simulações em colunas de lixiviação. Tese (Doutorado em Ciências) - Escola de Engenharia de São Carlos, Universidade de São Paulo. São Carlos, 2014.

COSTA FILHO, W.D.; BORBA, A.L.S.; MASCARENHAS, J.C. Monitoramento de aquíferos costeiros da Região Metropolitana do Recife. In: CONGRESSO BRASILEIRO DE ÁGUAS SUBTERRÂNEAS, 16, 2010, São Luís. Anais... São Luís: ABAS, 2010.

CPRH - AGÊNCIA ESTADUAL DE MEIO AMBIENTE. Sistema de Informações Geoambientais de Pernambuco. Disponível em: <http://sigcabure.cprh.pe.gov.br/> Acesso em 02 mar. 2017.

CPRM - COMPANHIA DE PESQUISA DE RECURSOS MINERAIS. Vulnerabilidade das Águas subterrâneas da Região Metropolitana do Recife. Recife, 1994.

. GEOSGB. Disponível em: <http://geosgb.cprm.gov.br/geosgb/sobre_geosgb.html>. Acesso em 18 mar. 2017.

EMBRAPA - EMPRESA BRASILEIRA DE PESQUISA AGROPECUÁRIA. Biblioteca Geoespacial. 2017. Disponível em: <http://geo.cnpma.embrapa.br/pesquisa_pt.aspx>. Acesso em 22 fev. 2017.

ESA, M.R.; HALOGA, A.; RIGAMONTI, L. Strategies for minimizing construction and demolition wastes in Malaysia. Resources, conservation and recycling, v.120, p. 219-229, 2017.

GAVA, T.; FINOTTI, A.R. Resíduos sólidos urbanos na rede de drenagem da bacia hidrográfica do rio do meio, Florianópolis/SC. Gestão Ambiental e Sustentabilidade, v.1, n.2, p. 79-101, jul./dez., 2012.

IBGE - INSTITUTO BRASILEIRO DE GEOGRAFIA E ESTATÍSTICA. Censo 2010. Disponivel em: <https://www.ibge.gov.br/estatisticas-novoportal/sociais/saude/9662-censo-demografico-2010.html?=\&t=o-que-e>. Acesso em: 08 mar. 2017

Hidrografia. Disponível em: < ftp://geoftp.ibge.gov.br/cartas_e_mapas/bases_cartograficas_continuas/bc250/versao2017/>. Acesso em 08 mar. 2017.
INPE - INSTITUTO NACIONAL DE PESOUISAS ESPACIAIS. TOPODATA: Banco de dados geomorfométricos do Brasil. Disponível em: <http://www.dsr.inpe.br/topodata/acesso.php>. Acesso em $20 \mathrm{fev}$ 2017.

JÚNIOR, L.C.P.; SOARES, H.L.T.; CASTRO, S.S. Vulnerabilidade natura e risco de contaminação do aquifero Bauru no município de Rio Verde/GO. Águas subterrâneas, v. 29, n.2, p. 129-145, 2015.

LAWSON, N.; DOUGLAS, I.; GARVIN, S.; MCGRATH, C.; MANNING, D.; VETTERLEIN, J. Recycling construction and demolition wastes: a UK perspective. Environmental management and Health, v.12, n.2, p. 146-157, 2001.

ORNELAS, A.R. Aplicação de métodos de análise especial na gestão dos resíduos sólidos urbanos. 2011. 101 p. Dissertação (Mestrado em Análise e Modelagem de Sistemas Ambientais) - Instituto de Geociências, Universidade Federal de Minas Gerais. Belo Horizonte, 2011.

PERNAMBUCO. Plano Hidroambiental da bacia hidrográfica do rio Capibaribe. Resumo executivo. Recife, 2010.

Plano Metropolitano de Resíduos Sólidos. Secretaria das Cidades. Recife, 2011.

RECIFE. Decreto $n^{\circ} 27.399$, de 27 de Setembro de 2013. Regulamenta as unidades de recebimento de Resíduos Sólidos oriundos de pequenos geradores, no âmbito do Município do Recife. Diário Oficial do Município de Recife, 2013.

SANTOS, D.S. Diagnóstico da gestão dos resíduos de construção e demolição e seus impactos ambientais no município de Jaboatão dos Guararapes/PE. 2015. 166 p. Dissertação (Mestrado em Engenharia Civil) - Escola Politécnica de Pernambuco, Universidade de Pernambuco. Recife, 2015.

SANTOS, H. N.; CÂNDIDA, A.C.; FERREIRA, T.K.S. Ações referentes a gestão de resíduos da Construção Civil em Araguari-MG. In: ENCONTRO NACIONAL DOS GEÓGRAFOS, 16, 2010, Porto Alegre. Anais.. Porto Alegre: AGB, 2010.

SECTMA - SECRETARIA DE CIÊNCIA, TECNOLOGIA E MEIO AMBIENTE. Diagnóstico do meio físico e biótico e mapa do uso e ocupação do solo do núcleo metropolitano do litoral pernambucano. Relatório de consultoria. Recife, 2006.

WIENS, I.K. A gestão de resíduos da construção civil: iniciativas na bacia hidrográfica Tietê-Jacaré e uma proposta para o município de Bauru (SP). 2008. 155 p. Dissertação (Mestrado em Engenharia de Produção) - Universidade Estadual Paulista Júlio de Mesquisa Filho). Bauru, 2008. 